\title{
Paliperidone palmitate injection for the acute and maintenance treatment of schizophrenia in adults
}

\author{
Shiyun Kim' \\ Hugo Solari² \\ Peter J Weiden ${ }^{2}$ \\ Jeffrey R Bishop' \\ 'Department of Pharmacy Practice, \\ University of Illinois at Chicago \\ College of Pharmacy, ${ }^{2}$ Department \\ of Psychiatry, University of Illinois \\ at Chicago College of Medicine, \\ Chicago, IL, USA
}

This article was published in the following Dove Press journal:

Patient Preference and Adherence

12 July 2012

Number of times this article has been viewed

Purpose: To review the use of paliperidone palmitate in treatment of patients with schizophrenia.

Methods: Published clinical trial data for the development and utilization of paliperidone palmitate for the treatment of schizophrenia were assessed in this review. Four short-term, randomized, double-blind, placebo-controlled trials investigated the efficacy of paliperidone palmitate in acute exacerbation of schizophrenia. Paliperidone palmitate was also studied as a maintenance treatment to prevent or delay relapse in stable schizophrenia. In addition, paliperidone palmitate was compared to risperidone long-acting injection for noninferiority in three studies.

Results: Paliperidone palmitate has been shown to be effective in reducing symptoms as measured by the Positive and Negative Syndrome Scale total scores in the four acute treatment studies. In the maintenance treatment studies, paliperidone palmitate was found to be more effective than placebo in preventing or delaying the time to first relapse in stable schizophrenia patients. In addition, paliperidone palmitate was shown to be noninferior to risperidone long-acting injection in two studies. It was shown to be reasonably well tolerated in all clinical trials. Acute treatment phase should be initiated with a dose of $234 \mathrm{mg}$ on day one and $156 \mathrm{mg}$ on day eight, followed by a recommended monthly maintenance dose of 39-234 mg based on efficacy and tolerability results from the clinical studies.

Conclusion: Providing an optimal long-term treatment can be challenging. Paliperidone palmitate can be used as an acute treatment even in outpatient setting, and it has shown to be well tolerated by patients. Also, it does not require overlapping oral antipsychotic supplementation while being initiated, and is dosed once per month.

Keywords: schizophrenia, antipsychotic, long-acting injection, paliperidone

\section{Introduction}

Long-acting injectable (LAI) antipsychotics have been available for many years but, until recently, options available were limited to first-generation "typical" antipsychotics. In the last decade, several formulations of the newer, second-generation "atypical" antipsychotics have become available (Figure 1). The goal of this review is to discuss the pharmacotherapy and clinical pharmacology of LAI antipsychotic therapies with a focus on paliperidone palmitate, a newer second-generation antipsychotic formulated for LAI. University of Illinois at Chicago College of Pharmacy, Department of Pharmacy Practice, $833 \mathrm{~S}$ Wood St Rm 164 (M/C886), Chicago, IL 606I2, USA

$\mathrm{Tel}+\mathrm{I} 3124133495$

Fax + I 3129960379

Email jbishop@uic.edu

\section{LAl antipsychotic formulations}

LAI antipsychotics are useful maintenance treatment options in patients with schizophrenia. These therapies have been available since the 1960s when the 


\section{Antipsychotic formulations*}

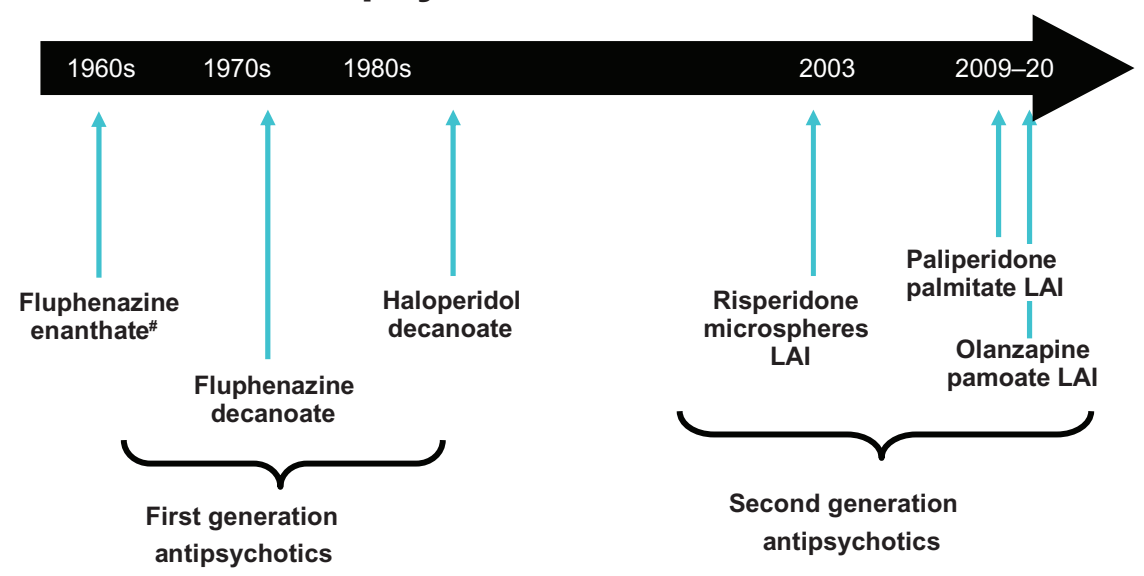

Figure I Timeline of availability of long-acting antipsychotic formulations that are Food and Drug Administration approved for use in the United States; other first-generation long-acting injectables are available in other countries.

Note: \#No longer available: replaced by fluphenazine decanoate. *FDA approved for use in USA.

Abbreviation: LAl, long-acting injection.

first-generation antipsychotic agent, fluphenazine, was introduced as a long-acting enanthate formulation. The commonly used fluphenazine decanoate and haloperidol decanoate long-acting agents soon followed. These agents are synthesized such that the parent drug is esterified to fatty acid chains that allow the formulation to be dissolved in sesame oil. Administration of the oily solution into deep muscle tissue as a "depot" injection results in a pool of medication that is subsequently hydrolyzed through an inflammatory response, which releases the drug into systemic circulation. ${ }^{1}$ Other available first-generation depot agents include perphenazine, pimozide, and flupenthixol. However, only fluphenazine and haloperidol are available agents in the United States due to Food and Drug Administration restriction. ${ }^{1}$ Second-generation LAIs such as risperidone microspheres, olanzapine pamoate, and paliperidone palmitate have also been formulated to gradually release active drug into the plasma from deep-tissue intramuscular injections. Unlike the sesame seed oil formulations of their first-generation predecessors, alternative delivery systems have been developed that no longer need to rely on covalent esterification to a fatty acid moiety. The paliperidone LAI formulation is the palmitate salt ester of paliperidone $(9-\mathrm{OH}-$ risperidone), and uses a nanocrystal technology formulation. In the pharmaceutical arena, nanoparticles are defined as having a size between 1-1000 nm. In this context, tiny drug crystals are created and dispersed in liquid media as an aqueous suspension (nanosuspensions). ${ }^{2}$ Paliperidone palmitate is a mixture of paliperidone palmitate enantiomers "wet-milled" into nanoparticles, which have low water solubility. ${ }^{3}$ After intramuscular injection, the suspended palmitate salt conju- gates are hydrolyzed to the active drug, which dissolves slowly into the systemic circulation. Due to the low solubility, slow dissolution occurs at the injection site. ${ }^{4}$

\section{Paliperidone palmitate pharmacokinetics}

The release of the drug into the systemic circulation begins as early as the first day of administration, and continues for up to 126 days. The apparent volume of distribution of paliperidone is $391 \mathrm{~L}$ based on population pharmacokinetic analyses. The plasma protein binding of racemic paliperidone is $74 \%{ }^{3}$

After a single intramuscular dose, plasma concentrations of paliperidone rise to reach maximum plasma concentration at a median time to maximum concentration of 13 days. ${ }^{4}$ Four metabolic pathways of paliperidone have been identified in vivo: (1) dealkylation, (2) hydroxylation, (3) dehydrogenation, and (4) benzisoxazole scission. ${ }^{5}$ In vitro studies in human liver microsomes revealed that paliperidone palmitate does not appreciably inhibit the metabolism of drugs metabolized by cytochrome P450 (CYP) isozymes and is not significantly metabolized by CYP1A2, CYP2A6, CPY2C8/9/10, CYP2D6, CYP2E1, CYP3A4, and CPY3A5. ${ }^{3,5}$ Paliperidone is predominantly excreted by the kidneys. According to paliperidone palmitate product labeling, 1 week following administration of a single oral dose of $1 \mathrm{mg}$ immediate-release ${ }^{14} \mathrm{C}$-paliperidone, $59 \%$ of the dose was excreted unchanged into urine, indicating that paliperidone is not extensively metabolized in the liver. Approximately $80 \%$ of the administered radioactivity was recovered in urine and 
$11 \%$ in feces..$^{5,6}$ Therefore, it is not expected to precipitate clinically significant pharmacokinetic interactions with other drugs. The median half-life of paliperidone following a single intramuscular dose of paliperidone palmitate (39-234 mg) is 25-49 days.

The pharmacokinetic profile of paliperidone palmitate may be influenced by factors such as injection site, injection volume, needle length, creatinine clearance, and body mass index (BMI). ${ }^{4}$ The most clinically relevant factor in this list is injection site. Two studies identified that deltoid muscle injections, compared to gluteal administration, resulted in higher initial median paliperidone plasma concentrations on day eight of treatment (after the second injection)., Intramuscular injection into the deltoid muscle resulted in a maximum plasma concentration that was $28 \%$ greater than the same dose administered into the gluteus. ${ }^{4}$ Once at steady state, there appears to be little difference in plasma paliperidone concentration between the two injection sites. ${ }^{7}$ This is important for clinicians to recognize because this greater maximum plasma concentration from the deltoid facilitates a rapid time to steady-state plasma concentrations, which is why deltoid administration is recommended for the first two injections. After the first two injections, patients and providers have a choice between deltoid and gluteal injection sites. It is also important to note that this may be a time when patients are more likely to experience side effects associated with peak plasma concentrations and to communicate with patients and caregivers appropriately. This certainly may apply to other LAI agents and is a general issue associated with LAIs. These studies also noted that using a longer needle (1.5 inch versus 1 inch) improved the likelihood of delivering accurate injections and, furthermore, that accuracy appears to be better from the deltoid site as compared to the gluteal route where the "hypovascularity" of subcutaneous tissue may alter the release profile of the drug., ${ }^{4,7}$

Reduced creatinine clearance is an indicator of renal dysfunction and therefore, is inversely correlated with the renal clearance of paliperidone. The results from pharmacokinetic analyses of oral paliperidone identified that the total clearance of the drug was reduced by $32 \%$ in those with mild renal impairment, $64 \%$ in those with moderate impairment, and $71 \%$ in those with severe impairment. ${ }^{4}$ When this information is translated to clinical application, creatinine clearance values $<80 \mathrm{~mL} /$ minute influence the dosing of the drug, as summarized in the "Dosing and Clinical Utilization" section below.

BMI is also related to pharmacokinetic parameters of paliperidone palmitate during the initial stages of treat- ment. Early in treatment, patients with higher baseline BMIs ( $\geq 25 \mathrm{~kg} / \mathrm{m}^{2}$ ) exhibit approximately 1.5-2-times lower median paliperidone plasma concentrations on day eight and day 36 than patients with normal baseline BMI $\left(<25 \mathrm{~kg} / \mathrm{m}^{2}\right)$ who are administered $156 \mathrm{mg}$ injections. ${ }^{8}$ However, the differences between higher and lower BMI groups do not appear to persist after repeated injections and may, therefore, not be of great clinical significance for longer-term treatment.

\section{Paliperidone palmitate pharmacodynamics}

Paliperidone palmitate is a centrally acting dopamine-D2 $\left(\mathrm{D}_{2}\right)$ receptor antagonist and a serotonin type-2A $\left(5-\mathrm{HT}_{2 \mathrm{~A}}\right)$ receptor antagonist. It is also active as an antagonist at $\alpha_{1}$ and $\alpha_{2}$ adrenergic receptors and histamine type-H1 receptors. Paliperidone palmitate has little affinity for cholinergic muscarinic or $\beta_{1}$ and $\beta_{2}$ adrenergic receptors. ${ }^{9}$ Comparisons with other antipsychotics with long-acting formulations that are available in the United States are presented in Table 1. Receptor binding profiles are often clinically helpful for clinicians when assessing the likelihood for specific side effects based on prior experiences with other agents. The first-generation haloperidol and fluphenazine antipsychotics are known for high $\mathrm{D}_{2}$ affinity and lower histamine type-1/ serotonin type-2C affinity, which is thought to be associated with a lower likelihood for weight gain than second-generation alternatives. Similarly, high $\mathrm{D}_{2}$ affinity in the absence of significant $5-\mathrm{HT}_{2 \mathrm{~A}}$ affinity is thought to be an underlying mechanism of a greater likelihood of extrapyramidal symptoms (EPS) for these first-generation agents as compared to second-generation options. Paliperidone has a similar receptor binding profile as risperidone, thus the choice between these two agents in a long-acting formulation may be more related to dosing logistics (once monthly for paliperidone versus every 2 weeks for risperidone) or insurance coverage/ financial considerations.

\section{Clinical studies of paliperidone palmitate}

The efficacy and safety of paliperidone palmitate in the acute treatment of schizophrenia has been assessed in one 9-week and three 13-week double-blind, randomized, placebocontrolled, fixed-dose studies. ${ }^{8,10-12}$ Prevention of relapse in schizophrenia was assessed in two long-term maintenance studies. ${ }^{13,14}$ Paliperidone palmitate has also been compared with risperidone LAI in three noninferiority studies. ${ }^{15-17}$

All clinical trials of paliperidone palmitate summarized herein used Positive and Negative Syndrome Scale (PANSS) 
Table I Receptor binding affinities (based on $\mathrm{K}_{\mathrm{i}}$ values) of long-acting antipsychotic injections ${ }^{19,45}$

\begin{tabular}{lllllll}
\hline Drug & Receptor & & & & \\
\cline { 2 - 6 } & $\mathbf{5}-\mathbf{H T} \mathbf{T}_{\mathbf{2 A}}$ & $\mathbf{D}_{\mathbf{2}}$ & $\mathbf{5 H T}_{\mathbf{2 A}} \mathbf{I} \mathbf{D}_{\mathbf{2}}$ & $\mathbf{M}_{\mathbf{1}}$ & $\boldsymbol{\alpha}_{\mathbf{1}}$ & $\mathbf{H}_{\mathbf{1}}$ \\
\hline Paliperidone (9-OH-risperidone) & High & High & High & Low & High & High \\
Olanzapine & High & Moderate & Low & Moderate & Moderate & High \\
Risperidone & High & High & High & Low & High & High \\
Haloperidol & Moderate & High & Moderate & Low & Moderate & Low \\
Fluphenazine & Moderate & High & Moderate & Low & High & Moderate \\
\hline
\end{tabular}

Notes: $K_{i}$ determined by in vitro radioligand competition assays; $K_{i}$ values: high $(0-10 \mathrm{~nm})$, moderate $(\mathrm{I} I-100 \mathrm{~nm})$, low ( $\left.\geq 100 \mathrm{~nm}\right)$; lower $K_{i}$ values indicate higher receptor affinity.

Abbreviations: $5-\mathrm{HT}_{2 \mathrm{~A}}$, serotonin type-2A; $\mathrm{D}_{2}$, dopamine type-2; $M_{1}$, muscarinic type-I; $\alpha_{1}$, $\alpha \mathrm{I}$ adrenergic; $\mathrm{H}_{1}$, histamine type-I.

total scores as primary outcome variables with additional analyses of positive and negative subscale measures of this assessment. Secondary outcome measures in these studies included the Clinical Global Impression of Severity (CGI-S) scale and the Personal and Social Performance (PSP) scale, which measures the severity of functional deficits. Recurrence and relapse events were evaluated in the longterm maintenance studies using fairly standard a priori criteria for relapse or impending relapse.

\section{Acute treatment}

Four (one 9-week and three 13-week) multicenter, doubleblind, placebo-controlled, fixed-dose studies evaluated the safety and efficacy of paliperidone palmitate using doses ranging from $39-234 \mathrm{mg}$ in patients with acute exacerbation of schizophrenia. The fixed doses of paliperidone palmitate in these studies were given on days one, eight, and 36 in the 9-week study, and additionally on day 64 of the 13-week studies. One study used the currently recommended initiation dose of $234 \mathrm{mg}$ of paliperidone palmitate or matching placebo via deltoid route on day one. ${ }^{12}$ Safety and efficacy were assessed in the 9-week study, while the three 13-week studies were specifically designed as dose-response studies. ${ }^{8,10-12}$

The first multicenter, randomized, double-blinded, placebo-controlled, dose-response study was a 13-week, phase III trial of 388 patients with schizophrenia. These patients had a diagnosis of schizophrenia - as established by the American Psychiatric Association's Diagnostic and Statistical Manual of Mental Disorder, Fourth Edition, Text Revision (DSM-IV-TR) - for at least 1 year before screening, a PANSS total score at baseline between 70-120, and a BMI $>17.0 \mathrm{~kg} / \mathrm{m}^{2}$. Otherwise, the patients were reported to be in good health. ${ }^{8}$ As summarized in Table 2, participants were treated with paliperidone palmitate $78 \mathrm{mg}, 156 \mathrm{mg}$, or $234 \mathrm{mg}$ versus placebo with PANSS assessments completed before and after completion of the treatment. PANSS total scores for participants in the $78 \mathrm{mg}$ group did not differ from placebo.
Only the paliperidone palmitate $156 \mathrm{mg}$ dose treatment group showed significantly greater improvement in PANSS total score compared with placebo $(P<0.02)$. Secondary efficacy findings included significant improvement in PSP scores from baseline to endpoint for both the paliperidone palmitate $156 \mathrm{mg}(P<0.001)$ and $78 \mathrm{mg}(P=0.004)$ groups.

The mean (standard deviation [SD]) PSP score change from baseline for the paliperidone palmitate $156 \mathrm{mg}$ and $78 \mathrm{mg}$ groups was 4.8 (15.35) and 4.2 (13.21), respectively. CGI-S scale improvements were significant only in the paliperidone palmitate $156 \mathrm{mg}$ group $(P=0.01)$; however, the median decrease in CGI-S was 1.0 for both treatment groups. Due to medication kit allocation error in the paliperidone palmitate $234 \mathrm{mg}$ dose group, the efficacy and safety results for this group were not presented.

The second acute treatment study assessed the efficacy and safety of paliperidone palmitate compared to placebo in 247 patients. ${ }^{10}$ This was a 9-week, double-blind, placebo-controlled study where patients were randomized to receive gluteal injections of either placebo or fixed doses of $78 \mathrm{mg}$ or $156 \mathrm{mg}$ on days one, eight, and 36. Patients participating in this study had a diagnosis of schizophrenia - according to DSM-IV-TR criteria - for at least 1 year, a PANSS total score of 70-120 at screening (60-120 inclusive on day one before the start of the study), and a BMI range of $15-35 \mathrm{~kg} / \mathrm{m}^{2}$. As summarized in Table 2, participants treated with either dose of paliperidone palmitate had significant improvements from baseline in PANSS total score compared with placebo $(P \leq 0.001$, each dose versus placebo). Differentiation from placebo was identified at day eight, and maintained to endpoint for both doses. Mean PANSS total scores showed significant improvement at endpoint for both paliperidone palmitate treatment groups. In the paliperidone palmitate $78 \mathrm{mg}$ and $156 \mathrm{mg}$ groups, the mean PANSS difference was -5.2 and -7.8 , respectively. CGI-S scores also improved at endpoint where $50 \%$ of the placebo group had a rating of marked, severe, 
Table 2 Paliperidone palmitate clinical trials of treatment for acute schizophrenia

\begin{tabular}{|c|c|c|c|c|}
\hline Authors & Study design & $\begin{array}{l}\text { Treatment } \\
\text { allocation }\end{array}$ & Efficacy findings & Comments \\
\hline Gopal et $\mathrm{al}^{8}$ & $\begin{array}{l}\text { I } 3 \text { weeks, phase III } \\
\mathrm{N}=388 \\
\mathrm{RCT}, \mathrm{DB}, \mathrm{PC} \\
\text { Following a washout and tolerability } \\
\text { period of } \leq 7 \text { days, patients were } \\
\text { randomized to receive one of three } \\
\text { fixed doses of PP (78, I56, or } 234 \mathrm{mg} \text { ) } \\
\text { or placebo administered by gluteal } \\
\text { IM injection on days one, eight, } 36 \text {, } \\
\text { and } 64\end{array}$ & $\begin{array}{l}\text { Placebo } \\
\text { PP } 78 \text { mg } \\
\text { PP I } 56 \text { mg } \\
\text { PP } 234 \text { mg }\end{array}$ & $\begin{array}{l}\text { Mean PANSS change from } \\
\text { baseline/statistics: } \\
\text { Placebo }-3.5 \\
\text { PP } 78 \mathrm{mg}-6.9 \\
\text { PP I56 mg* -6.9 }(P<0.05) \\
\text { PP } 234 \mathrm{mg}-5.5 \\
\text { CGI-S scale improvement: } \\
\text { PP I56 mg* }(P=0.0 \mathrm{I}) \\
\text { PSP score improvement: } \\
\text { PP } 78 \mathrm{mg}^{*}(P=0.004) \\
\text { PP I56 mg* }(P<0.00 \mathrm{I})\end{array}$ & $\begin{array}{l}\text { PP treatment with } 78 \mathrm{mg} \text { and } \\
\text { I56 mg resulted in dose-related } \\
\text { improvement in total PANSS } \\
\text { score. Results associated with the } \\
\text { I56 mg dose were statistically } \\
\text { significant } \\
\text { Limited results available with the } \\
234 \mathrm{mg} \text { dose group }\end{array}$ \\
\hline Kramer et $\mathrm{al}^{10}$ & $\begin{array}{l}9 \text { weeks } \\
\mathrm{N}=247 \\
\mathrm{RCT}, \mathrm{DB}, \mathrm{PC} \\
\text { Following a 5-day washout phase } \\
\text { and a 7-day oral run-in period, patients } \\
\text { were randomized to receive gluteal } \\
\text { IM injections of PP doses (78 } \mathrm{mg} \\
\text { or I56 mg) or placebo on days one, } \\
\text { eight, and } 36\end{array}$ & $\begin{array}{l}\text { Placebo } \\
\text { PP } 78 \text { mg } \\
\text { PP I } 56 \text { mg }\end{array}$ & $\begin{array}{l}\text { Mean PANSS change from } \\
\text { baseline/statistics: } \\
\text { Placebo }+6.2 \\
\text { PP } 78 \mathrm{mg}^{*}-5.2(P \leq 0.00 \mathrm{I}) \\
\text { PP I56 mg* }-7.8(P \leq 0.00 \mathrm{I}) \\
\text { CGI-S scale improvement: } \\
\text { PP } 78 \mathrm{mg}^{*}(P \leq 0.004) \\
\text { PP I56 mg* }(P \leq 0.004)\end{array}$ & $\begin{array}{l}\text { PP was well tolerated in both } \\
78 \text { mg and I } 56 \text { mg doses. } \\
\text { Rapid onset of symptom response } \\
\text { was seen by day eight compared } \\
\text { to placebo. Both treatment groups' } \\
\text { response was maintained } \\
\text { throughout the study }\end{array}$ \\
\hline Nasrallah et al" & $\begin{array}{l}\text { I } 3 \text { weeks, phase III } \\
\mathrm{N}=518 \\
\mathrm{RCT}, \mathrm{DB} \text {, parallel-group } \\
\text { Following a } \leq 7 \text {-day screening, washout, } \\
\text { and tolerability period, patients were } \\
\text { randomized to one of three fixed PP } \\
\text { doses ( } 39,78 \text {, or } 156 \mathrm{mg} \text { ) or placebo. } \\
\text { Injections were administered } \\
\text { by gluteal IM injection on days one, } \\
\text { eight, } 36 \text {, and } 64\end{array}$ & $\begin{array}{l}\text { Placebo } \\
\text { PP } 39 \mathrm{mg} \\
\text { PP } 78 \mathrm{mg} \\
\text { PP I56 mg }\end{array}$ & $\begin{array}{l}\text { Mean PANSS change from } \\
\text { baseline/statistics: } \\
\text { Placebo }-7.0 \\
\text { PP } 39 \text { mg*-13.6 }(P<0.05) \\
\text { PP } 78 \text { mg* }-13.2(P<0.05) \\
\text { PP I56 mg* -16.I }(P \leq 0.001) \\
\text { CGI-S scale improvement: } \\
\text { PP } 39 \text { mg* (P=0.003) } \\
\text { PP } 78 \text { mg* }(P=0.006) \\
\text { PP I56 mg* }(P=0.002)\end{array}$ & $\begin{array}{l}\text { PP treatment groups resulted } \\
\text { in statistically significant } \\
\text { responses compared to placebo } \\
\text { and improvement in total } \\
\text { PANSS score }\end{array}$ \\
\hline Pandina et al ${ }^{12}$ & $\begin{array}{l}\text { I } 3 \text { weeks, phase III } \\
\mathrm{N}=652 \\
\mathrm{RCT}, \mathrm{DB}, \mathrm{PC} \\
\text { Following a } \leq 7 \text {-day washout and } \\
\text { tolerability period, patients were } \\
\text { randomized to one of three PP doses } \\
\text { or placebo: on day I (deltoid IM } \\
\text { injection) } 234 \mathrm{mg} \text { PP or placebo; } \\
\text { on days eight, } 36 \text {, and } 64 \text { (deltoid } \\
\text { or gluteal IM injection) } 234,156 \text {, or } \\
39 \mathrm{mg} \text { PP or placebo }\end{array}$ & $\begin{array}{l}\text { Placebo } \\
\text { PP } 39 \mathrm{mg} \\
\text { PP I } 56 \mathrm{mg} \\
\text { PP } 234 \mathrm{mg}\end{array}$ & 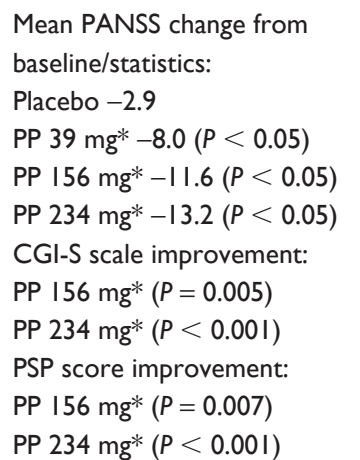 & $\begin{array}{l}\text { PP treatment group had significant } \\
\text { dose-related improvement in total } \\
\text { PANSS score when treatment } \\
\text { was provided at an initial dose } \\
\text { of } 234 \mathrm{mg} \text { in the deltoid, followed } \\
\text { by fixed-dose injections } \\
(39,156 \text {, or } 234 \mathrm{mg}) \text { into gluteal } \\
\text { or deltoid muscle I week later } \\
\text { and then once per month as } \\
\text { maintenance treatment }\end{array}$ \\
\hline
\end{tabular}

Note: *Statistically significant improvement.

Abbreviations: CGI-S, Clinical Global Impression of Severity; DB, double-blind; IM, intramuscular; PANSS, Positive and Negative Syndrome Scale; PC, parallel-controlled; PP, paliperidone palmitate; PSP, Personal and Social Performance Scale; RCT, randomized controlled trial.

or extremely severe at endpoint versus $37 \%$ and $32 \%$ for the paliperidone palmitate $78 \mathrm{mg}$ and $156 \mathrm{mg}$ groups, respectively. Both paliperidone palmitate treatment doses were statistically superior to placebo in reducing CGI-S scores $(P \leq 0.004)$.

The third multicenter, randomized, double-blind study of paliperidone palmitate and placebo assessed efficacy, safety, and tolerability over a 13 -week treatment period. ${ }^{11}$
Fixed doses of $39 \mathrm{mg}, 78 \mathrm{mg}$, and $156 \mathrm{mg}$ paliperidone palmitate versus placebo were administered as gluteal injections on days one and eight, and then every 4 weeks (days 36 and 64) in 518 adult patients. Patients participating in this study had similar eligibility as in prior studies, ie, meeting DSM-IV-TR criteria for schizophrenia for at least 1 year. At enrollment, patients had a PANSS total score of 70-120 with a BMI $>15.0 \mathrm{~kg} / \mathrm{m}^{2}$. Of the 518 randomized patients, 
only $263(51 \%)$ patients completed the study. As noted in Table 2, all paliperidone palmitate dose groups showed significant improvement versus placebo in the primary efficacy measurement of PANSS.

Interestingly, a notable disparity was detected in the distribution of baseline BMI across participating countries, but not across treatment groups: $75 \%$ of United States patients were obese $\left(\mathrm{BMI} \geq 30 \mathrm{~kg} / \mathrm{m}^{2}\right.$ ) or overweight (BMI $\geq 25-30 \mathrm{~kg} / \mathrm{m}^{2}$ ) compared to $42 \%$ of Romanian, $41 \%$ of Russian, 35\% of Bulgarian, and 23\% of South African participants. The mean baseline BMI of patients from the United States was $30.2 \mathrm{~kg} / \mathrm{m}^{2}$ (range $17-60 \mathrm{~kg} / \mathrm{m}^{2}$ ) compared with $24.2-30.2 \mathrm{~kg} / \mathrm{m}^{2}$ (range $16-38 \mathrm{~kg} / \mathrm{m}^{2}$ ) for participants from other countries. Patients enrolled at sites outside the United States had greater improvements in PANSS total scores than those from sites in the United States. This finding indicated a trend towards differential treatment effect by BMI category. Based on pharmacokinetic data summarized earlier, this may have resulted in differences in plasma concentrations early in treatment.

The final efficacy and safety study of paliperidone palmitate was a 13-week investigation of 652 patients with schizophrenia. ${ }^{12}$ This was a multicenter, randomized, doubleblind, and placebo-controlled investigation where participants received paliperidone palmitate at $234 \mathrm{mg}$ or placebo in the deltoid muscle on day one, with assigned fixed dose or placebo in the deltoid or gluteal muscle on day eight, and then once monthly. Patients participating in this study included patients with an acute exacerbation of schizophrenia with total PANSS scores of 60-120 at baseline. Patients with BMI $\geq 40 \mathrm{~kg} / \mathrm{m}^{2}$ were excluded from this study. A total of 652 patients were randomly assigned $(1: 1: 1: 1)$ to each dose group of $39 \mathrm{mg}, 156 \mathrm{mg}$, or $234 \mathrm{mg}$ paliperidone palmitate or placebo. PANSS total score from baseline to endpoint improved significantly in all three dose groups versus placebo $(P \leq 0.034)$. The mean PSP scores showed a dose-related improvement in the paliperidone palmitate treatment groups, which was significant in the $156 \mathrm{mg}$ and $234 \mathrm{mg}$ groups. Mean (SD) changes in PSP scores from baseline to endpoint were noted as follows: 2.9 (15.3) in the $39 \mathrm{mg}$ group, 6.1 (13.6) in the $156 \mathrm{mg}$ group, 8.3 (14.7) in the $234 \mathrm{mg}$ group versus 1.7 (15.6) in the placebo group. A significant improvement in CGI-S scores was seen only in the paliperidone palmitate $156 \mathrm{mg}$ and $234 \mathrm{mg}$ groups $(P \leq 0.005)$. The median (range) changes in CGI-S from baseline were noted as follows: -1.0 $(-3 ; 2)$ in the $39 \mathrm{mg}$ group, $-1.0(-4 ; 2)$ in the $156 \mathrm{mg}$ group, and $-1.0(-4 ; 3)$ in the $234 \mathrm{mg}$ group compared to $0.00(-3 ; 2)$ in the placebo group.

\section{Maintenance treatment}

Relapse prevention in schizophrenia was assessed in a longterm maintenance study of recurrence prevention consisting of five phases which were summarized and published as part of two analyses. ${ }^{13,14}$ These five phases included: (1) a screening and oral tolerability testing phase of up to 7 days, (2) a 9-week open-label transition phase during which eligible patients were switched from their previous antipsychotic to receive once-monthly injections of paliperidone palmitate, (3) a 24-week open-label maintenance phase, (4) a double-blind phase when stabilized patients were randomized in a 1:1 ratio to receive either paliperidone palmitate or placebo until they experienced relapse, and finally (5) an optional 52-week open-label extension phase. ${ }^{14}$ This longterm maintenance study was the most extensive clinical trial program of any LAIs to date.

In the first phase of the study, participating patients had a diagnosis of schizophrenia - per DSM-IV-TR criteria - for at least 1 year before screening and a PANSS total score $<120$ at screening and baseline. ${ }^{13}$ Both symptomatic and stable patients were eligible. The patients remained in the doubleblind phase until they experienced a relapse, withdrew from the study, or until the first phase of the study was completed. The primary efficacy variable was the time-to-first relapse during the double-blind phase. Relapse was predefined as "time to first emergence" of one or more of the following: "significant" increase in total PANSS scores, psychiatric hospitalization, deliberate self-injury, violent behavior, and suicidal ideation. This study also evaluated changes in total PANSS and CGI-S scores.

The participants who were randomized to continue on paliperidone palmitate during the double-blind phase experienced a significant delay in time-to-relapse compared to the placebo group. The median time-to-relapse in the placebo group (50\% of patients) was 163 days, and not estimable for paliperidone palmitate due to the small number of relapses observed ( $<25 \%$ of patients experienced a relapse). Relapse event rates were also significantly lower in the treatment group versus the placebo group (10\% versus $34 \%$, respectively). Of note, this study was terminated early by an Independent Data Monitoring Committee because of the robust findings identified in the interim efficacy results in favor of the paliperidone treatment group.

Patients from the above double-blind study who experienced a relapse remained relapse free until the double-blind study stopped early for efficacy, and those who completed the double-blind study were eligible for an open-label extension study of 52 weeks, which is the longest published study of 
paliperidone palmitate to date. ${ }^{14} \mathrm{~A}$ total of 388 patients participated in this open-label extension and 288 patients (74\%) completed the study. Patients received gluteal injections of paliperidone palmitate once every 4 weeks at a starting dose of $78 \mathrm{mg}$ followed by $39 \mathrm{mg}, 78 \mathrm{mg}, 117 \mathrm{mg}$, or $156 \mathrm{mg}$ flexible dosing. Improvements seen from baseline to endpoints were observed on PANSS, PSP scale, and CGI-S assessment. This study demonstrated improvements in PANSS total scores from baseline for patients treated with paliperidone palmitate (mean change $\pm \mathrm{SD}-4.3 \pm 15.43$ ). The greatest improvement in PANSS total scores were seen in patients who were switched from placebo to paliperidone palmitate during the open-label extension study (mean change \pm SD $-8.4 \pm 19.43)$. Overall, $6 \%(n=22)$ of patients discontinued the study due to lack of efficacy, and worsening of schizophrenia was reported by $6 \%$ of the patients. Of the $61 \%$ of patients $(n=235)$ who were continuously exposed to paliperidone palmitate from the start of the transition phase to the end of the open-label extension study, $70 \%$ had $>1.5$ years of continuous exposure and $33 \%$ had $>2$ years of continuous exposure. The most frequently used paliperidone palmitate dose was $156 \mathrm{mg}$. The results of this study demonstrated that paliperidone palmitate administered as a once-monthly gluteal injection was well tolerated and accepted by patients who continued treatment for a year.

\section{Comparative trials}

Paliperidone palmitate has been studied in three comparative efficacy trials with risperidone LAI. ${ }^{15-17}$ These studies were designed as noninferiority trials with similar efficacy outcomes observed between the two agents.

The first comparative efficacy study was a 53-week, double-blind, randomized, parallel-group, multicenter trial to assess noninferiority of paliperidone palmitate compared to risperidone LAI in patients with schizophrenia. ${ }^{15}$ Primary efficacy outcome variables included changes on the PANSS total scores as well as relapse. Participants received flexible dosing of paliperidone palmitate 39-156 mg once-monthly injection or risperidone LAI biweekly injections of $25 \mathrm{mg}$ on days eight and 22 , and $25-50 \mathrm{mg}$ flexible dosing starting from day 36, with allowed oral supplementation. Patients in the risperidone LAI group also received oral risperidone supplementation doses of $1-6 \mathrm{mg} /$ day during the first 4 weeks of treatment and $1-4 \mathrm{mg} /$ day at any dose increase for up to 3 weeks.

The mean change $( \pm \mathrm{SD})$ from baseline to endpoint in PANSS total score was lower $(-11.6 \pm 21.22)$ in the paliperidone palmitate group compared to the risperidone LAI group (-14.4 \pm 19.76$)$. Relapse occurred in $25 \%$ of patients in the paliperidone palmitate group and $18 \%$ of patients in the risperidone LAI group. The overall rates of treatmentemergent adverse events were similar in the paliperidone palmitate $(76 \%)$ and risperidone LAI (79\%) groups. In the efficacy comparison, paliperidone palmitate-treated participants demonstrated a less favorable response as compared to risperidone LAI; however, it is important to note that the doses of paliperidone palmitate used in this study may have been suboptimal or at least perhaps comparatively lower than risperidone LAI when conventional conversion estimates are applied.

The next comparative efficacy study was a 13 -week international, multicenter, randomized, double-blind, double-dummy, active-controlled, parallel-group, flexibledose trial designed to assess noninferiority of paliperidone palmitate versus risperidone LAI in adult patients with schizophrenia. ${ }^{16}$ In this study, patients were randomized to receive either paliperidone palmitate or risperidone LAI. Patients received paliperidone $234 \mathrm{mg}$ via deltoid intramuscular route on day one, $156 \mathrm{mg}$ on day eight, and then once-monthly flexible doses. Risperidone LAI subjects received their first injection of $25 \mathrm{mg}$ on day eight followed by a biweekly injection on days $22,36,50,64$, and 78. Risperidone LAI patients received $1-6 \mathrm{mg}$ /day oral risperidone on days $1-28$, whereas paliperidone palmitate patients received oral placebo. The mean (SD) PANSS total score change from baseline was similar in the two groups starting on day four: -18.6 (15.45) in the paliperidone palmitate group and $-17.9(14.24)$ in the risperidone LAI group. The primary and secondary efficacy findings of this study resulted in similar improvements in patients with acute schizophrenia. The incidence of treatment-emergent adverse events was similar in both treatment groups (57.9\% in the paliperidone palmitate group and $52.8 \%$ in the risperidone LAI group). The frequency of study drug discontinuation was low in both treatment groups $3 \%$ in the paliperidone palmitate group and $1.2 \%$ in the risperidone LAI group). Akathisia (both groups $<5 \%$ ) and tremor (both groups $<3 \%$ ) were the most commonly reported EPS-related adverse events, with no difference between the groups. The analysis of this study provided support for the conclusion that paliperidone palmitate has a similar efficacy (per noninferiority analysis) to risperidone.

The final comparison study published to date was an open-label, single-blinded, parallel-group, noninferiority study of paliperidone palmitate and risperidone LAI in adult Chinese patients with acute schizophrenia. ${ }^{17}$ Eligible patients 
$(\mathrm{N}=452)$ with schizophrenia were randomized (1:1) to receive either paliperidone palmitate or risperidone LAI for 13 weeks. Paliperidone palmitate doses were administered using a flexible dosing strategy including $78 \mathrm{mg}, 156 \mathrm{mg}$, or $234 \mathrm{mg}$. Risperidone LAI was also dosed flexibly. Risperidone LAI-treated patients received oral risperidone supplementation of 1-6 mg/day at initiation, with risperidone LAI dose increases. The mean dose administered to individual patients throughout the study was 115.8 (range 87.5-137.5) $\mathrm{mEq}$ (the mean dose of $115.8 \mathrm{mEq}$ is equal to a dose of approximately $180 \mathrm{mg}$ as measured by currently approved doses) for the paliperidone palmitate group and $29.8 \mathrm{mg}$ (range 25-37.5) for the risperidone LAI group. The mean change in total PANSS scores from baseline was -23.6 for the paliperidone palmitate group and -26.9 for the risperidone LAI group. The mean CGI-S scale change from baseline to endpoint was -1.5 in the paliperidone palmitate group and -1.7 in the risperidone LAI group. This study also demonstrated similar efficacy for paliperidone palmitate and risperidone LAI according to noninferiority analyses.

\section{Safety and tolerability findings}

The most common paliperidone palmitate-associated adverse events from pooled analyses of double-blind, placebocontrolled, acute treatment trials (rates of $\geq 5 \%$ in the treatment group and more than twice the placebo rate) were: EPS $(0 \%-5 \%$ versus $1 \%)$, injection site-reactions $(0 \%-10 \%$ versus $2 \%$ ), dizziness ( $2 \%-6 \%$ versus $1 \%)$, and somnolence/ sedation $(5 \%-7 \%$ versus $3 \%){ }^{3}$ The frequency of subjects who discontinued due to adverse events in the four fixeddose, double-blind, placebo-controlled trials was reported to be $5.0 \%$ and $7.8 \%$ for paliperidone palmitate versus placebo, respectively. ${ }^{8,10-12}$ In the 52-week open-label extension study, the most frequent adverse events were insomnia (7\%), worsening of schizophrenia $(6 \%)$, nasopharyngitis $(6 \%)$, headache $(6 \%)$, and $\geq 7 \%$ weight increase of baseline body weight $(6 \%) .{ }^{14}$ Taken as a whole, these findings suggest that paliperidone palmitate is relatively well tolerated in the context of these clinical trials.

\section{EPS-related adverse events}

In the largest 13-week dose-response study to date, akathisia was the most commonly reported EPS event across all the treatment groups ( $<6 \%$ of patients). ${ }^{12}$ In both shorter term 9-13 week trials ${ }^{8,10-12}$ and maintenance treatment studies, ${ }^{13,14}$ the incidence of EPS-related events was $<10 \%$ across paliperidone dose groups suggesting a favorable EPS tolerability profile for most patients.

\section{Weight changes}

Metabolic effects such as weight gain are considered to be the most clinically significant adverse events associated with many second-generation antipsychotics. ${ }^{18}$ As newer agents and formulations become available, differences in weight gain or metabolic side effects are now used as deciding factors when choosing among antipsychotics. In the four acute treatment studies, the paliperidone palmitate group ( $4 \%-13 \%)$ gained $\geq 7 \%$ of their baseline bodyweight versus the placebo group $(2 \%-5 \%){ }^{8,10-12}$ The mean weight increase ranged from $+0.4 \mathrm{~kg}$ to $+1.9 \mathrm{~kg}$ on paliperidone palmitate versus -0.3 to $-0.7 \mathrm{~kg}$ on placebo. In the relapse prevention maintenance study, $\geq 7 \%$ weight increase occurred in approximately twice as many patients in the paliperidone palmitate group compared to the placebo group (23\% versus $12 \%$ ) at the double-blind endpoint. ${ }^{13}$ Similarly, in the 52-week open-label extended study, mean (SD) change in weight from baseline to endpoint for the 388 patients was +0.9 (4.3) kg. ${ }^{14}$ Thus, during shorter treatment duration, the weight gained from paliperidone palmitate is relatively moderate when considering weight gain estimates that have been observed for other oral agents like clozapine and olanzapine. As previously described, the trajectory for increasing weight extends from 6-12 months and even beyond with paliperidone palmitate observations consistent with these prior observations. ${ }^{14}$ It should also be noted that the weight changes in relapse prevention trials may vastly underreport weight gain as they do not include the stabilization phase prior to randomization. Many subjects at initial stabilization are switched from other antipsychotics that have weight gain that attenuates the degree of weight gain experienced during subsequent treatment as compared to that experienced by antipsychotic naive patients. Nonetheless, the weight gain estimates reported for paliperidone seem to place it in a low to moderate weight gain category relative to other commonly used antipsychotics, although direct comparison studies are needed to substantiate this categorization.

\section{Prolactin levels}

Paliperidone palmitate elevates prolactin levels, and the elevation in levels may persist during the maintenance phase due to $\mathrm{D}_{2}$ receptor antagonism. ${ }^{19}$ Based on the pooled data from the four acute studies, elevated prolactin levels were common in the paliperidone palmitate treatment groups compared to the placebo groups and appeared to be dose-related. ${ }^{8,10-12}$ Despite prolactin levels being elevated, side effects related to prolactin elevation were not 
commonly reported. In the three acute studies, side effects related to elevated prolactin levels were seen in $\leq 2 \%$ of the paliperidone palmitate groups versus $\leq 1 \%$ in the placebo groups. ${ }^{8,10,11}$ The potential prolactin-related adverse events were also low in the fourth acute study: one case in the placebo groups and two cases in the treatment groups. ${ }^{10}$ In the relapse prevention study, potential prolactin-related adverse events were noted in $2 \%$ in the paliperidone palmitate groups and $1 \%$ in the placebo groups. ${ }^{13}$ In this study, mean prolactin levels increased in paliperidone palmitate patients $(+12.7 \mathrm{ng} / \mathrm{mL}$ in women and $+3.7 \mathrm{ng} / \mathrm{mL}$ in men), whereas the placebo groups noted a decline in prolactin levels $(-16.6 \mathrm{ng} / \mathrm{mL}$ in women and $-9.2 \mathrm{ng} / \mathrm{mL}$ in men). In the 52-week open-label study, $3 \%$ of patients were reported to have prolactin-related adverse events and the highest mean prolactin level was seen in the female population. ${ }^{14}$ The mean (SD) prolactin level changes from baseline for men was +1.6 (13.7) $\mathrm{ng} / \mathrm{mL}$ and +6.5 (39.4) $\mathrm{ng} / \mathrm{mL}$ in women. The most common reported events were amenorrhea and galactorrhea.

\section{Injection-site reactions/pain}

Injection site pain in the 13 -week studies was $<8 \%$ in paliperidone-treated patients as opposed to $<4 \%$ treated with placebo injections. ${ }^{8,12}$ Gluteal injections of paliperidone palmitate were reported to be well tolerated in the 52-week open-label extension study. In this study, injection-site reaction was reported to be "absent" in $82 \%-87 \%$ of the patients. $^{14}$

\section{Cardiac related - QT prolongation}

Paliperidone palmitate "causes a modest increase in the corrected QT (QTc) interval" and it is noted in the product labeling that it should be avoided in combination with drugs that are known to prolong QTc including class 1A or class III antiarrhythmic medications or any other class of medications known to prolong QTc. ${ }^{3}$ However, in the four acute treatment studies, no QTc interval changes were noted or reported..$^{8,10-12}$ No patients had a linear derived QTc interval $>480$ milliseconds or an increase of $>60$ milliseconds from baseline during this study. This suggests that conduction abnormalities, as measured by electrocardiography and QTc estimates, are relatively uncommon in healthy patients with schizophrenia who are administered paliperidone palmitate. Given the warnings present in the product labeling, clinicians ought to assess personal or family histories of cardiac conduction abnormalities or other cardiovascular diseases in patients who are candidates for therapy with this drug and formulation.

\section{Dosing and clinical utilization}

Paliperidone palmitate is indicated in the United States for the acute and maintenance treatment of schizophrenia in adults. In the literature, paliperidone doses are sometimes expressed as milligram equivalents ( $\mathrm{mEq}$ ) of paliperidone. Therefore, $25,50,75,100$, and $150 \mathrm{mEq}$ paliperidone palmitate are equivalent to $39,78,117,156$, and $234 \mathrm{mg}$ of paliperidone palmitate, respectively.

For patients who have never taken oral paliperidone or oral/injectable risperidone, tolerability should be established with oral paliperidone or oral risperidone prior to initiating treatment with paliperidone palmitate LAI. Conversions between oral paliperidone and paliperidone palmitate are included in Table 3. The recommended initial regimen is a $234 \mathrm{mg}$ injection on day one followed by $156 \mathrm{mg}$ on day eight, each administered into the deltoid muscle. The reason for deltoid administration for the initiation dose is related to the pharmacokinetics of the release profile from this site early in treatment. It is recommended to use a 1 -inch 23 -gauge needle in patients $<90 \mathrm{~kg}$ and 1.5 -inch 22 -gauge needle in those $\geq 90 \mathrm{~kg}$. Monthly maintenance doses of paliperidone palmitate range from 39-234 mg injected into the deltoid or gluteal muscle. No oral supplementation is required while paliperidone palmitate is being initiated. The day eight dose may be administered \pm 2 days and monthly doses \pm 7 days without a clinically significant impact. Paliperidone palmitate can be initiated the day after discontinuing a previous oral antipsychotic agent., 3 Paliperidone palmitate can be initiated at the next scheduled injection date, and monthly thereafter, in patients switching from other antipsychotic LAI agents. ${ }^{20}$

Paliperidone palmitate has not been extensively studied in patients with renal impairment. Based on pharmacokinetic simulations and a limited number of observations (see earlier information on pharmacokinetic effects), the dose of paliperidone palmitate should be reduced in patients with mild renal impairment. In patients with mild renal impairment

Table 3 Doses of oral and injectable paliperidone needed to attain similar concentration at steady-state ${ }^{14}$

\begin{tabular}{|c|c|c|}
\hline & \multicolumn{2}{|l|}{ Formulation } \\
\hline & $\begin{array}{l}\text { Paliperidone } \\
\text { extended-released } \\
\text { tablet }\end{array}$ & $\begin{array}{l}\text { Paliperidone } \\
\text { palmitate } \\
\text { long-acting injection }\end{array}$ \\
\hline Dosing frequency & Once daily & Once every 4 weeks \\
\hline \multirow[t]{3}{*}{ Dose } & $3 \mathrm{mg}$ & $39-78 \mathrm{mg}$ \\
\hline & $6 \mathrm{mg}$ & $117 \mathrm{mg}$ \\
\hline & $12 \mathrm{mg}$ & $234 \mathrm{mg}$ \\
\hline
\end{tabular}

Adapted from Invega ${ }^{\circledR}$ Sustenna ${ }^{\mathrm{TM}}$ product information. ${ }^{3}$ 
(creatinine clearance $50-80 \mathrm{~mL} /$ minute), the recommended initial dose is $156 \mathrm{mg}$ on treatment day one and $117 \mathrm{mg}$ a week later. A following monthly injection of $78 \mathrm{mg}$ is recommended. Paliperidone palmitate is not recommended in patients with moderate or severe renal impairment (creatinine clearance $<50 \mathrm{~mL} /$ minute).

No dose adjustment is required in patients with mild or moderate hepatic impairment. At this time, no published data exists regarding its use in severe hepatic impairment. ${ }^{20}$

\section{The role of LAl antipsychotics in clinical practice}

Long-acting antipsychotics such as paliperidone palmitate may be considered for patients requiring maintenance therapy, which includes most patients with schizophrenia. LAIs provide consistent drug delivery that is independent of a patient's ability or desire to take regularly scheduled oral medications. This minimizes the risk of a patient deliberately or inadvertently taking too much or too little medication and minimizes dosage deviations. In cases where patients fail to receive a scheduled injection, clinicians are able to immediately identify when interruptions in treatment begin. Similarly, in the context of symptom recurrence or exacerbation, examining a patient's LAI history can assist the clinician in ruling out nonadherence as a possible cause, thereby facilitating more informed decisions about subsequent therapeutic adjustments. ${ }^{21}$

Many treatment providers mistakenly think that LAIs are undesirable to patients because of the need to get an injection or because of the stigma associated with an injection. In reality, many patients actually prefer the long-acting route, particularly if they are already engaged in treatment. ${ }^{22,23}$ Furthermore, second-generation LAI antipsychotics, compared to the first-generation LAIs, are likely to have an improved treatment satisfaction and greater acceptance by patients with schizophrenia due to a better tolerability profile. ${ }^{24}$

In clinical practice, many patients are not presented with an option for long-acting formulations until later in treatment after nonadherence is observed, or they may even be selected as treatment-resistant patients in hopes of overcoming covert nonadherence. When LAIs are viewed as part of a treatment delivery program, as opposed to a direct pharmacologic intervention, they are often received as acceptable and desirable treatment options, even in patients who are receiving treatment during their "first episode." 22

One of the most common challenges encountered in the management of patients with schizophrenia is nonadherence and the recognition and understanding of this phenomenon is important for clinicians as they strategize treatment plans and the potential role for LAI therapies. It is very common for patients to take their medications only intermittently or not at all. Poor and partial adherence to oral antipsychotics has been observed in $35 \%$ of patients as early as in the first 4-6 weeks of treatment. ${ }^{21}$ The rate of nonadherence increases over time and within 2 years of hospital discharge, $75 \%$ of patients may be categorized as nonadherent. ${ }^{25}$ Nonadherence is a multifactorial problem that may result from factors such as greater illness severity (ie, negative symptoms and cognitive deficits), poor patient and caregiver relationship or communication, substance abuse, medication-related side effects, and lack of insight. ${ }^{26}$ Patients who lack insight into their illness are less likely to be engaged in treatment and are more likely to underestimate the benefits of medication and to discontinue prescribed therapies. ${ }^{27}$ Inconsistency with medication exacerbates the multiple challenges that are already faced in the management of the patient with schizophrenia. The broader consequences of inadequate treatment further underscore the importance of maintaining treatment. As medication adherence decreases, rates of hospitalization, self-harm, and aggressive behaviors increase. ${ }^{28-31}$ Addressing barriers to adherence in patients with schizophrenia is challenging as there are a variety of patient-specific reasons that may result in a failure to maintain a consistent pharmacologic treatment regimen. ${ }^{32}$ Potential barriers to LAI use and benefits of using paliperidone palmitate are presented in Table 4.

The selection of a specific LAI antipsychotic for a given patient is a combination of pharmacologic and nonpharmacologic factors. When assessing treatment options it may be useful to compare some of the dosing and formulation characteristics of available medications (Table 5). One advantage of the LAI formulation of paliperidone palmitate is that it can

Table 4 Issues and barriers to long-acting injectable implementation and benefits of using paliperidone palmitate

\begin{tabular}{|c|c|}
\hline Potential barriers & Paliperidone palmitate \\
\hline $\begin{array}{l}\text { Restricted pharmacologic } \\
\text { options }\end{array}$ & $\begin{array}{l}\text { Additional option from the newer } \\
\text { antipsychotic category }\end{array}$ \\
\hline $\begin{array}{l}\text { Converting from short } \\
\text { half-life oral to long } \\
\text { half-life long-acting } \\
\text { injectable }\end{array}$ & $\begin{array}{l}\text { Initiation strategy seems to be effective } \\
\text { for rapid conversion }\end{array}$ \\
\hline $\begin{array}{l}\text { Need to convert after } \\
\text { the acute psychotic } \\
\text { episode is already treated }\end{array}$ & $\begin{array}{l}\text { Paliperidone palmitate is indicated for } \\
\text { both acute and maintenance therapy }\end{array}$ \\
\hline $\begin{array}{l}\text { Lag-time before the } \\
\text { benefits of long-acting } \\
\text { route }\end{array}$ & $\begin{array}{l}\text { Release of the drug starts as early as } \\
\text { day one of administration/does not need } \\
\text { oral supplementation during initiation }\end{array}$ \\
\hline
\end{tabular}


Table 5 Comparing the long-acting antipsychotic injections

\begin{tabular}{|c|c|c|c|c|c|}
\hline & Dosing interval & $\begin{array}{l}\text { Loading } \\
\text { dose option }\end{array}$ & $\begin{array}{l}\text { Oral dose overlap } \\
\text { (if loading dose } \\
\text { option is not selected) }\end{array}$ & $\begin{array}{l}\text { Route } \\
\text { of administration }\end{array}$ & Monitoring and safety \\
\hline Paliperidone palmitate ${ }^{3}$ & Every 4 weeks & Yes & Not required & $\begin{array}{l}\text { Deltoid for loading } \\
\text { then either } \\
\text { gluteal/deltoid }\end{array}$ & $\begin{array}{l}\text { Establishment of tolerance } \\
\text { to the medication by prior } \\
\text { oral administration required }\end{array}$ \\
\hline Olanzapine pamoate ${ }^{46}$ & Every $2-4$ weeks & Yes & Not required & Gluteal only & $\begin{array}{l}\text { Post injection monitoring } \\
\text { required for } 3 \text { hours. } \\
\text { Patient care program required } \\
\text { Establishment of tolerance } \\
\text { to the medication by prior } \\
\text { oral administration } \\
\text { recommended }\end{array}$ \\
\hline $\begin{array}{l}\text { Risperidone } \\
\text { long-acting injection }{ }^{47}\end{array}$ & Every 2 weeks & No & Required & Gluteal/deltoid & $\begin{array}{l}\text { Establishment of tolerance } \\
\text { to the medication by prior } \\
\text { oral administration required }\end{array}$ \\
\hline Haloperidol decannoate ${ }^{48}$ & Every 4 weeks & Yes & Recommended & Gluteal/deltoid & $\begin{array}{l}\text { Monitor for hypotension } \\
\text { post injection }\end{array}$ \\
\hline Fluphenazine decanoate ${ }^{49}$ & Every $2-4$ weeks & Not established & Recommended & Gluteal/deltoid & $\begin{array}{l}\text { Monitor for hypotension } \\
\text { post injection }\end{array}$ \\
\hline
\end{tabular}

be used in an acute setting and it can simplify the medication regimen for patients and caregivers (Table 4).

Patients with schizophrenia often do not conceptualize their symptoms in the same way as their treating clinician. ${ }^{33}$ Therefore, it is essential for clinicians to carefully assess and consider patient-focused perspectives such as insight into their illness, satisfaction with care, quality of life, and acceptability/understanding of the role of pharmacotherapy, including LAIs. It has been proposed that quality of life assessments should include information on psychosocial, somatic, functional, and social domains, but there is still controversy on how to best measure quality of life. ${ }^{34}$ Relevant to the role of LAI antipsychotics, a survey of outpatients identified that $87 \%$ of patients receiving one of these formulations would choose to continue their injectable medication. ${ }^{35}$ While some patients prefer injectable medications because they facilitate treatment (ie, it is easier to remember than taking pills daily), ${ }^{36}$ other patients fear the pain associated with intramuscular injections, consider injections to be intrusive, ${ }^{34,37}$ or perceive long-acting antipsychotic medications to be a coercive treatment when compared to oral medications. ${ }^{23}$ Carefully evaluating how patients view or understand the role of pharmacotherapy helps clinicians to build relationships to facilitate positive treatment planning and implementation.

The putative benefit of LAI antipsychotics over oral counterparts is an ongoing debate. Studies comparing paliperidone palmitate to oral paliperidone have not yet been published. In general there appear to be many reports of the benefits of
LAI antipsychotics, but also a number of studies showing no added benefit over oral medications. For example, previous published studies evaluating long-term outcome with risperidone LAI versus oral antipsychotic agents did not show differential benefits to risperidone LAI. ${ }^{38-40}$ Additionally, Gaebel et al published relapse prevention with risperidone LAI versus oral therapy quetiapine, where there appeared to be no difference in relapse between the two treatments although adherence was greater in the risperidone LAI treatment group. ${ }^{41}$ Outside the context of randomized controlled studies, epidemiological studies and meta-analyses suggest that patients taking LAI antipsychotics have fewer hospitalizations and may be at lower risk for relapse. ${ }^{42,43}$ The differences in the results of these studies may be due to the nature of the LAI intervention in that it is linked more closely to the type of services provided. This underscores the importance of clinical context and patient-specific factors, which may not be able to be assessed in the structure of randomized controlled studies.

\section{Conclusion}

Providing an optimal long-term treatment via choosing the appropriate LAI agent can be challenging. The conventional antipsychotic depot formulations have high propensity to cause EPS. The second-generation antipsychotic paliperidone palmitate has been introduced with a tolerability profile that may be favorable compared to the typical first-generation antipsychotics, and tolerability and efficacy similar to risperidone LAI ${ }^{44}$ No comparisons to date have been made 
between paliperidone palmitate and olanzapine pamoate, another second-generation LAI antipsychotic.

The efficacy of paliperidone palmitate in the acute treatment of schizophrenia has been demonstrated in four short-term trials. However, there are only a few long-term trials assessing maintenance treatment thus far, and the doseresponse relationships and strategies for converting from other treatments to paliperidone is an area for additional research. Efficacy appears to be similar to risperidone LAI and the overall tolerability profile seems to be in the mild to moderate range for most antipsychotic-associated side effects, with the exception of prolactin elevation which is very common for paliperidone.

Paliperidone palmitate offers several advantages relative to other available LAI antipsychotics: it can be used as an acute treatment in the outpatient setting, and it has been shown to be well tolerated by patients. Also, it does not require overlapping oral antipsychotic supplementation while it is being initiated, and it offers the convenience of once-monthly administration. The injection volume is small and it offers dosing flexibility. It also gives the patient an option to receive the injection via the deltoid or gluteal route. ${ }^{7}$ However, one of the challenges of this LAI would be the uncertainties for achieving an optimal dosing regimen based on the clinical data available.

\section{Acknowledgments}

Dr Bishop is supported by grant K08MH083888.

\section{Disclosure}

Shiyun Kim and Hugo Solari report no conflicts of interest in this work. Dr Weiden has received research/grant support from: NIMH, Ortho-McNeil Janssen, Novartis, Sunovion, Roche/Genetech and is a consultant for Delpor, Genentech, Ortho-McNeil Janssen, and Sunovion. Dr Bishop has received research/grant support from Ortho-McNeil Janssen and is supported by grant K083888 from NIMH.

\section{References}

1. Weiden PJ, Solari H, Kim S, Bishop JR. Long-acting injectable antipsychotics and the management of nonadherence. Psychiatr Ann. 2011;41(5):271-278.

2. Junghanns J, Muller R. Nanocrystal technology, drug delivery and clinical applications. Int J Nanomedicine. 2008;3(3):295-309.

3. Once-monthly Invega ${ }^{\circledR}$ Sustenna $^{\mathrm{TM}}$ (paliperidone palmitate) extendedrelease injectable suspension [package insert]. Titusville, NJ: Janssen Pharmaceuticals; 2011.

4. Samtani MN, Vermeulen A, Stuyckens K. Population pharmacokinetics of intramuscular paliperidone palmitate in patients with schizophrenia: a novel once-monthly long-acting formulation of an atypical antipsychotic. Clin Pharmacokinet. 2009;48(9):585-600.
5. Vermeir M, Naessens I, Remmerie B, et al. Absorption, metabolism, and excretion of paliperidone, a new monoaminergic antagonist, in humans. Drug Metab Dispos. 2008;36(4):769-779.

6. Invega ${ }^{\circledR}$ paliperidone extended-release tablets [package insert]. Titusville, NJ: Janssen Pharmaceuticals; 2006.

7. Hough D, Lindenmayer JP, Gopal S, et al. Safety and tolerability of deltoid and gluteal injections of paliperidone palmitate in schizophrenia. Prog Neuropsychopharmacol Biol Psychiatry. 2009;33(6):1022-1031.

8. Gopal S, Hough DW, Xu H, et al. Efficacy and safety of paliperidone palmitate in adult patients with acutely symptomatic schizophrenia: a randomized, double-blind, placebo-controlled, dose-response study. Int Clin Psychopharmacol. 2010;25(5):247-256.

9. Shayegan DK, Stahl SM. Atypical antipsychotics: matching receptor profile to individual patient's clinical profile. CNS Spectr. 2004; 9(10 Suppl 11):6-14.

10. Kramer M, Litman R, Hough D, et al. Paliperidone palmitate, a potential long-acting treatment for patients with schizophrenia. Results of a randomized, double-blind, placebo-controlled efficacy and safety study. Int J Neuropsychopharmacol. 2010;13(5):635-647.

11. Nasrallah HA, Gopal S, Gassmann-Mayer C, et al. A controlled, evidence-based trial of paliperidone palmitate, a long-acting injectable antipsychotic, in schizophrenia. Neuropsychopharmacology. 2010;35(10):2072-2082.

12. Pandina GJ, Lindenmayer JP, Lull J, et al. A randomized, placebo-controlled study to assess the efficacy and safety of three doses of paliperidone palmitate in adults with acutely exacerbated schizophrenia. J Clin Psychopharmacol. 2010;30(3):235-244.

13. Hough D, Gopal S, Vijapurkar U, Lim P, Morozova M, Eerdekens M. Paliperidone palmitate maintenance treatment in delaying the time-torelapse in patients with schizophrenia: a randomized, double-blind, placebo-controlled study. Schizophr Res. 2010;116(2-3):107-117.

14. Gopal S, Vijapurkar U, Lim P, Morozova M, Eerdekens M, Hough D. A 52-week open-label study of the safety and tolerability of paliperidone palmitate in patients with schizophrenia. J Psychopharmacol. 2011;25(5):685-697.

15. Fleischhacker WW, Gopal S, Lane R, et al. A randomized trial of paliperidone palmitate and risperidone long-acting injectable in schizophrenia. Int J Neuropsychopharmacol. July 22, 2011. [Epub ahead of print.]

16. Pandina G, Lane R, Gopal S, et al. A double-blind study of paliperidone palmitate and risperidone long-acting injection in adults with schizophrenia. Prog Neuropsychopharmacol Biol Psychiatry. 2011;35(1):218-226.

17. Li H, Rui Q, Ning X, Xu H, Gu N. A comparative study of paliperidone palmitate and risperidone long-acting injectable therapy in schizophrenia. Prog Neuropsychopharmacol Biol Psychiatry. 2011;35(4):1002-1008.

18. Kroeze WK, Hufeisen SJ, Popadak BA, et al. H1-histamine receptor affinity predicts short-term weight gain for typical and atypical antipsychotic drugs. Neuropsychopharmacology. 2003;28(3):519-526.

19. Schotte A, Janssen PF, Gommeren W, et al. Risperidone compared with new and reference antipsychotic drugs: in vitro and in vivo receptor binding. Psychopharmacology (Berl). 1996;124(1-2):57-73.

20. Gopal S, Gassmann-Mayer C, Palumbo J, Samtani MN, Shiwach R, Alphs L. Practical guidance for dosing and switching paliperidone palmitate treatment in patients with schizophrenia. Curr Med Res Opin. 2010;26(2):377-387.

21. Nasrallah HA. The case for long-acting antipsychotic agents in the post-CATIE era. Acta Psychiatr Scand. 2007;115(4):260-267.

22. Weiden PJ, Schooler NR, Weedon JC, Elmouchtari A, Sunakawa A, Goldfinger SM. A randomized controlled trial of long-acting injectable risperidone vs continuation on oral atypical antipsychotics for first-episode schizophrenia patients: initial adherence outcome. J Clin Psychiatry. 2009;70(10):1397-1406.

23. Patel MX, de Zoysa N, Bernadt M, Bindman J, David AS. Are depot antipsychotics more coercive than tablets? The patient's perspective. J Psychopharmacol. 2010;24(10):1483-1489. 
24. Fleischhacker WW. Second-generation antipsychotic long-acting injections: systematic review. Br J Psychiatry Suppl. 2009;52: S29-S36.

25. Weiden PJ, Rapkin B, Zygmunt A, Mott T, Goldman D, Frances A. Postdischarge medication compliance of inpatients converted from an oral to a depot neuroleptic regimen. Psychiatr Serv. 1995; 46(10):1049-1054.

26. Love RC. Strategies for increasing treatment compliance: the role of long-acting antipsychotics. Am J Health Syst Pharm. 2002;59 (22 Suppl 8):S10-S15.

27. Heinrichs DW, Cohen BP, Carpenter WT Jr. Early insight and the management of schizophrenic decompensation. J Nerv Ment Dis. 1985;173(3):133-138.

28. Weiden PJ, Kozma C, Grogg A, Locklear J. Partial compliance and risk of rehospitalization among California Medicaid patients with schizophrenia. Psychiatr Serv. 2004;55(8):886-891.

29. Alia-Klein N, O'Rourke TM, Goldstein RZ, Malaspina D. Insight into illness and adherence to psychotropic medications are separately associated with violence severity in a forensic sample. Aggress Behav. 2007;33(1):86-96.

30. Herings RM, Erkens JA. Increased suicide attempt rate among patients interrupting use of atypical antipsychotics. Pharmacoepidemiol Drug Saf. 2003;12(5):423-424.

31. Velligan DI, Weiden PJ, Sajatovic M, et al. The expert consensus guideline series: adherence problems in patients with serious and persistent mental illness. J Clin Psychiatry. 2009;70 Suppl 4:1-46.

32. Weiden PJ. Understanding and addressing adherence issues in schizophrenia: from theory to practice. J Clin Psychiatry. 2007; 68 Suppl 14:14-19.

33. Larsen EB, Gerlach J. Subjective experience of treatment, sideeffects, mental state and quality of life in chronic schizophrenic out-patients treated with depot neuroleptics. Acta Psychiatr Scand. 1996;93(5):381-388.

34. Kane JM, Aguglia E, Altamura AC, et al. Guidelines for depot antipsychotic treatment. European Neuropshychopharmacology Consensus Conference in Siena, Italy. Eur Neuropsychopharmacol. 1998;8(1):55-66.

35. Pereira S, Pinto R. A survey of the attitudes of chronic psychiatric patients living in the community toward their medication. Acta Psychiatr Scand. 1997;95(6):464-468.
36. Wistedt B. How does the psychiatric patient feel about depot treatment, compulsion or help? Nord J Psychiatry. 1995;49(Suppl 35): 41-46.

37. Glazer WM, Kane JM. Depot neuroleptic therapy: an underutilized treatment option. J Clin Psychiatry. 1992;53(12):426-433.

38. Chue P, Eerdekens M, Augustyns I, et al. Comparative efficacy and safety of long-acting risperidone and risperidone oral tablets. Eur Neuropsychopharmacol. 2005;15(1):111-117.

39. Macfadden W, Ma YW, Haskins JT, Bossie CA, Alphs L. A prospective study comparing the long-term effectiveness of injectable risperidone long-acting therapy and oral aripiprazole in patients with schizophrenia. Psychiatry (Edgmont). 2010;7(11):23-31.

40. Rosenheck RA, Krystal JH, Lew R, et al. Risperidone and oral antipsychotics in unstable schizophrenia. N Engl J Med. 2011;364(9): 842-851.

41. Gaebel W, Schreiner A, Bergmans P, et al. Relapse prevention in schizophrenia and schizoaffective disorder with risperidone long-acting injectable vs quetiapine: results of a long-term, open-label, randomized clinical trial. Neuropsychopharmacology. 2010;35(12):2367-2377.

42. Schooler NR. Relapse and rehospitalization: comparing oral and depot antipsychotics. J Clin Psychiatry. 2003;64 Suppl 16:14-17.

43. Tiihonen J, Haukka J, Taylor M, Haddad PM, Patel MX, Korhonen P. A nationwide cohort study of oral and depot antipsychotics after first hospitalization for schizophrenia. Am J Psychiatry. 2011;168(6):603-609.

44. Nasrallah HA. Atypical antipsychotic-induced metabolic side effects: insights from receptor-binding profiles. Mol Psychiatry. 2008;13(1):27-35

45. Richelson E, Souder T. Binding of antipsychotic drugs to human brain receptors focus on newer generation compounds. Life Sci. 2000;68(1):29-39.

46. Zyprexa Relprevv ${ }^{\circledR}$ (olanzapine) for extended release injectable suspension [package insert]. Indianapolis, IN: Eli Lilly and Company; 2010.

47. Risperdal Consta ${ }^{\circledR}$ (risperdone) long-acting injection [package insert]. Titusville, NJ: Janssen Pharmaceuticals; 2011.

48. Haloperidol decanoate injection [package insert]. Irvine, CA: Teva Parenteral Medicines; 2009.

49. Fluphenazine decanoate injection [package insert]. Bedford, $\mathrm{OH}$ : Bedford Laboratories; 2010.
Patient Preference and Adherence

\section{Publish your work in this journal}

Patient Preference and Adherence is an international, peer-reviewed, open access journal focusing on the growing importance of patient preference and adherence throughout the therapeutic continuum. Patient satisfaction, acceptability, quality of life, compliance, persistence and their role in developing new therapeutic modalities and compounds to

\section{Dovepress}

optimize clinical outcomes for existing disease states are major areas of interest. This journal has been accepted for indexing on PubMed Central. The manuscript management system is completely online and includes a very quick and fair peer-review system. Visit http://www.dovepress.com/ testimonials.php to read real quotes from published authors. 